\title{
Experimental investigation into methane hydrate production during three-dimensional thermal huff and puff
}

\author{
Xiao-Sen Li ${ }^{\text {a,b,*, }}$ Yi Wang a,b,c , Li-Ping Duan ${ }^{\mathrm{d}}$, Gang Li ${ }^{\mathrm{a}, \mathrm{b}}$, Yu Zhang ${ }^{\mathrm{a}, \mathrm{b}}$, Ning-Sheng Huang ${ }^{\mathrm{a}, \mathrm{b}}$, \\ Duo-Fu Chen ${ }^{\text {e }}$ \\ ${ }^{a}$ Key Laboratory of Renewable Energy and Gas Hydrate, Guangzhou Institute of Energy Conversion, Chinese Academy of Sciences, Guangzhou 510640, PR China \\ ${ }^{\mathrm{b}}$ Guangzhou Center for Gas Hydrate Research, Chinese Academy of Sciences, Guangzhou 510640, PR China \\ ${ }^{\mathrm{c}}$ Graduate University of Chinese Academy of Sciences, Beijing 100083, PR China \\ ${ }^{\mathrm{d}}$ Institute of Scientific and Technical Information of China, Beijing 100038, PR China \\ ${ }^{\mathrm{e}}$ Guangzhou Institute of Geochemistry, Chinese Academy of Sciences, Guangzhou 510640, PR China
}

\section{A R T I C L E I N F O}

\section{Article history:}

Received 21 September 2011

Received in revised form 6 January 2012

Accepted 11 January 2012

Available online 13 February 2012

\section{Keywords:}

Methane hydrate

Three-dimensional

Thermal huff and puff

Production behavior

\begin{abstract}
A B S T R A C T
In this work, the decomposition behaviors of methane hydrate in the porous media are investigated in the three-dimensional cubic hydrate simulator (CHS) using the huff and puff method with a single well with the different injection temperatures and different injection time. The changes of the system pressure are analyzed by using the biggest increasing degree of the system pressure during injection stage (PII) and the biggest increasing degree of the system pressure during soaking stage (PIS), and the result shows that the injection time has more obvious effect on the system pressure than the injection temperature. The cumulative volume of the produced gas increases with the increases of the injection temperature and injection time. The higher injection temperature results in the smaller volume of the produced water; whereas the higher injection time results in the bigger volume of the produced water. In addition, increasing the injection temperature and injection time may not enhance the thermal efficiency and energy efficiency. The optimum period for the gas production is the first 4-5 cycles. The highest energy efficiency can be obtained at the injection temperature of $130^{\circ} \mathrm{C}$ and the injection time of 5 min. Furthermore, the experiment verifies that a moving decomposition boundary occurs in the hydrate decomposition process, and there is a maximum decomposition boundary with the thermal huff and puff cycle. In addition, the injected heat does not diffuse isotropically.
\end{abstract}

(c) 2012 Elsevier Ltd. All rights reserved.

\section{Introduction}

Natural gas hydrates (NGHs) are crystalline solids composed of water and gas. The gas molecules (guests) are trapped in water cavities (host) that are composed of hydrogen-bonded water molecules. Typical natural gas molecules include methane, ethane, propane, and carbon dioxide, etc. Natural gas hydrate deposits involve mainly $\mathrm{CH}_{4}$, and occur in the permafrost and in deep ocean sediments, where the necessary conditions of low temperatures and high pressures exist for hydrate stability [1]. Estimates of the world hydrate reserves are very high, and vary from $0.2 \times 10^{15}$ to $120 \times 10^{15} \mathrm{~m}^{3}$ of methane at STP (Standard Temperature and Pressure). However, even with the most conservative estimates, it is clear that the energy in these hydrate deposits is likely to be signif-

\footnotetext{
* Corresponding author at: Key Laboratory of Renewable Energy and Gas Hydrate, Guangzhou Institute of Energy Conversion, Chinese Academy of Sciences, Guangzhou 510640, PR China. Tel.: +86 20 87057037; fax: +86 2087034664.

E-mail address: lixs@ms.giec.ac.cn (X.-S. Li).
}

icant compared to all other fossil fuel deposits, and was considered to be a potential strategic energy resource [2-4].

In order to exploit this large energy resource, the researchers have proposed many methods, such as: (1) the thermal stimulation method [5-7], in which the hydrate reservoirs are heated above the equilibrium hydrate decomposition temperature by using in situ combustion or injecting hot water, steam or hot salt water to decompose the hydrates; (2) the depressurization method [8], in which the hydrate reservoir pressure is reduced below the equilibrium decomposition pressure to decompose the hydrates; (3) the chemical injection method [9], in which the chemicals (such as methanol or ethylene glycol) are injected to change the equilibrium hydrate decomposition conditions, thus to decompose the hydrates. The other two recent ideas which need experimental and field confirmation include: $\mathrm{CO}_{2}$ replacement [10], to inject liquid $\mathrm{CO}_{2}$ into offshore hydrate reservoirs by forming $\mathrm{CO}_{2}$ hydrate and replacing the methane gas, and gas lift [11], to lift the hydrate particle as a solid from the sea bottom. Gas production strategies often involve the combinations of these dissociation methods [12], and it is considered that the combination of the depressurization and 
thermal stimulation is a promising method [13]. The Mallik 2002 well demonstrated the proof of the concept that it is possible to recover energy from permafrost hydrates combining the dissociation techniques of the depressurization and the thermal stimulation [14-16].

Till now, the experimental studies on methane hydrate production has been limited to one-dimensional $[5,6]$ and two-dimensional [17] simulations. In fact, the actual natural gas hydrate reservoir is a three-dimensional mine. Therefore, in order to understand more realistic behavior of gas hydrate production, three-dimensional experimental simulation of natural gas hydrate production, especially three-dimensional investigation into the decomposition behavior of gas hydrate, is significant. However, little literature on this aspect has been reported so far.

In this work, the novel developed three-dimensional cubic hydrate simulator (CHS) for the production of gas hydrate is used to investigate into the decomposition behaviors of methane hydrate during the thermal huff and puff experiments through a single vertical well. The huff and puff method, also known as the cyclic steam stimulation (CSS), was accidentally discovered by Shell Oil Company in 1960 during a Venezuela recovery project, and is widely used in the oil industry to enhance oil recovery [18-20]. The hot water, hot brine or steam huff and puff method is a special form of the thermal stimulation method in conjunction with the depressurization for gas production from the hydrate deposit. The change characteristics of the temperature, pressure, resistance ratio and other related parameters during the huff and puff cycles are obtained, and the advantage and disadvantage of the thermal huff and puff method are analyzed.

\section{Experiment}

\subsection{Experimental apparatus}

Fig. 1 shows the schematic of the experimental apparatus. The experimental apparatus mainly consists of a reactor, a water bath, a back pressure regulator and an aqueous solution injection system, a gas injection system, a water/gas separator, some measurement units and a data acquisition system. The core component of the apparatus is a three-dimensional high-pressure reactor made of stainless steel 316 , with pressure range up to $25 \mathrm{MPa}$. The inside of the reactor is cubic, with the edge length of $180 \mathrm{~mm}$, and effective volume of $5.8 \mathrm{~L}$. The three-dimensional reactor, called as the cubic hydrate simulator (CHS), is placed in a water bath with constant temperature. The reactor is equipped with multiple sets of the measuring points and wellheads, and the layout of the measuring points and the wellheads is divided into three layers, namely top (A), middle (B), and bottom (C), with each layer having a total of 25 points. Fig. $2 a$ and $b$ shows the distributions of the temperature and resistance measuring points of the different layers and production wellheads within the three-dimensional reactor. It can be seen that there are a total of $25 \times 3$ temperature measuring points, $12 \times 3$ resistance measuring points and $1 \times 3$ central vertical wells along the centerline of the reactor, and the measuring points are evenly distributed in the reactor. In this experiment, the inlet for the heat injection is the B wellhead in middle layer (B) along the centerline of the reactor, and the outlet for the gas and water production is the A wellhead in top layer (A). Pressure is measured by the Trafag NAT8251.7425 type pressure sensor, with measuring range $0-25 \mathrm{MPa}$, and accuracy $\pm 0.02 \mathrm{MPa}$. A pressure transducer at the outlet for the gas and water production is used to measure the outlet pressure, and the other pressure transducer at the center of the bottom of the reactor is used to measure the pressure of the bottom of the hydrate-bearing layer. Temperature is measured by the Pt100 platinum resistor temperature sensor, with measuring range -20 to $200^{\circ} \mathrm{C}$, and accuracy $\pm 0.1^{\circ} \mathrm{C}$. Resistance is measured by $\mathrm{H} 28$ resistivity meter. Two gas flow meters, which are used to measure the cumulative gas injected into the $\mathrm{CHS}$, the gas production rate and the cumulative gas produced from the vessel, are both of D07-11CM, 0-10 L/min, $\pm 2 \%$ from "seven star company". The thermometers, pressure transducers, gas flow meters, were calibrated using a mercury thermometer with the tolerance of $\pm 0.01{ }^{\circ} \mathrm{C}$, a pressure test gauge with the error of $\pm 0.05 \%$, and a wet gas meter with the accuracy of $\pm 10 \mathrm{ml} / \mathrm{min}$, respectively. A metering pump "Beijing Chuangxintongheng” HPLC $\mathrm{P} 3000 \mathrm{~A}$ with the range of $50 \mathrm{ml} / \mathrm{min}$ can withstand pressures of up to $30 \mathrm{MPa}$. An inlet liquid container with the inner volume of $10 \mathrm{~L}$ is used to contain the deionized water used in the experiments. In order to protect the metering pump from corrosion by the hot brine or the chemicals, three middle containers are used for the solution injection, and the inner volume of each container is $4 \mathrm{~L}$. A back-pressure regulator (the pressure range of $0-30 \mathrm{MPa}$,

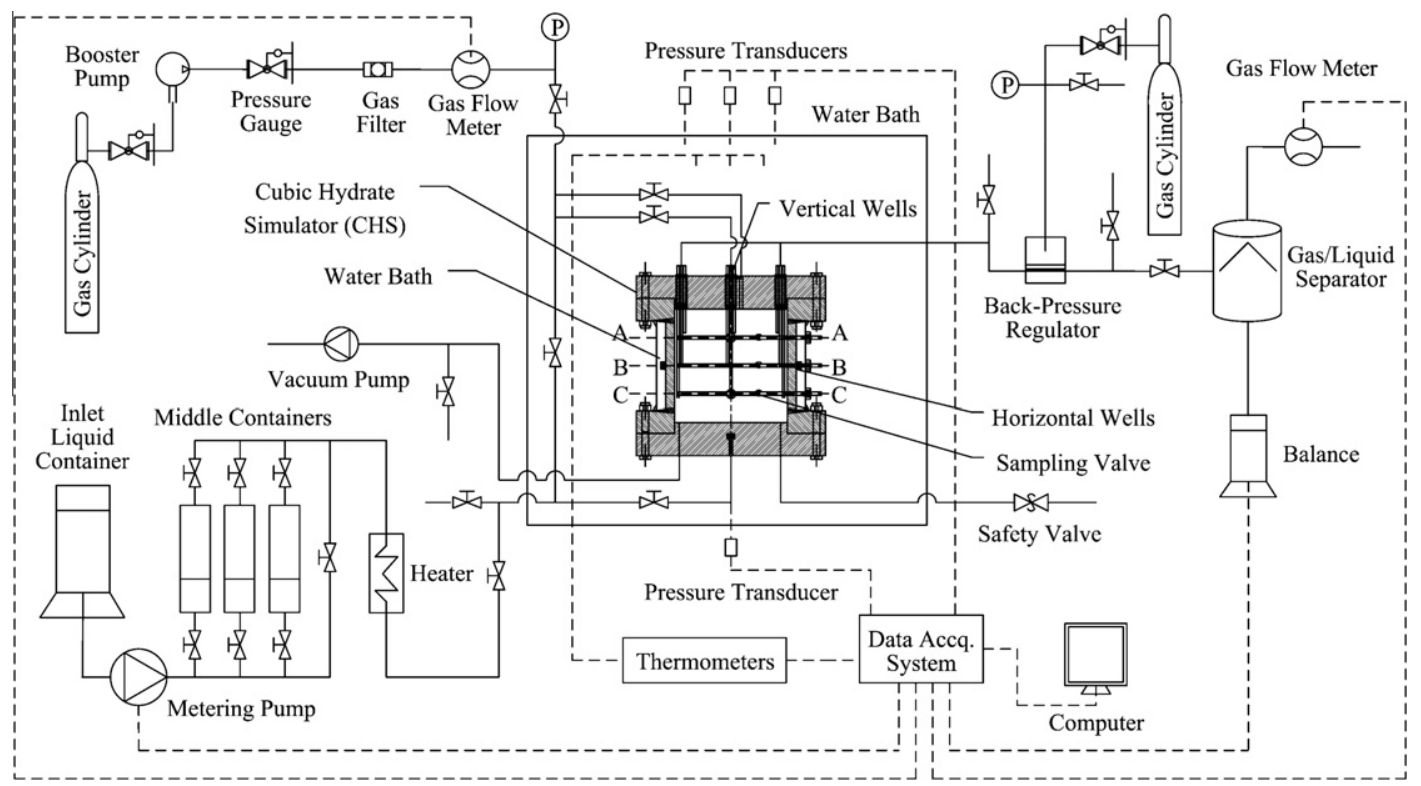

Fig. 1. Schematic of three-dimensional experimental apparatus. 


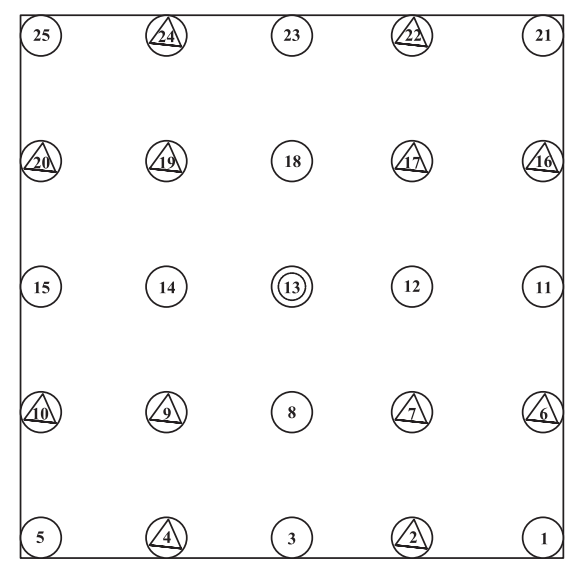

○-Temperature measuring point, $\Delta$-Resistance measuring point, (O)-Wellhead

(a)

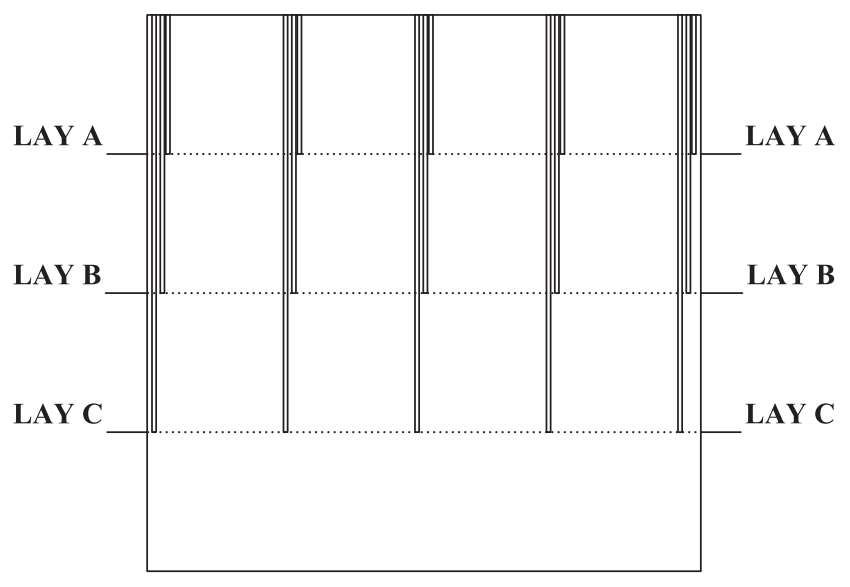

(b)

Fig. 2. Distributions of temperature, resistance measuring points and production wellhead of each layer within the three-dimensional reactor.

$\pm 0.02 \mathrm{MPa}$ ) connected to the outlet of the CHS is used to control the pressure of the production well. A gas cylinder is used to provide the driving force of the back-pressure regulator. A balance, used to measure the mass of liquid produced from the CHS, is Sartorius BS $2202 \mathrm{~S}, 0-2200 \mathrm{~g}, \pm 0.01 \mathrm{~g}$. The data acquisition system records the temperature, pressure, amount of the cumulative gas produced from the vessel, gas production rate and liquid production rate. The liquid injection rate can be controlled by the metering pump, which is connected to the data acquisition system. In this work, the methane gas with its purity of $99.99 \%$ is used.

\subsection{Experimental methods}

Quartz sand with the quality of $8162 \mathrm{~g}$, the particle size from 300 to $450 \mu \mathrm{m}$ and the porosity of approximately $48 \%$ is tightly packed in the CHS as the porous media. Deionized water of $1537 \mathrm{ml}$ is injected to the CHS by the metering pump. The temperature of the water bath is set to a predetermined temperature required for the gas hydrate synthesis, which is $8.0^{\circ} \mathrm{C}$ in the current research [21]. The $13.4 \mathrm{~mol}$ of methane is then injected to pressurize the CHS to $20 \mathrm{MPa}$. The inlet and outlet valves of the CHS are closed to keep the system in a constant volume condition. There is a certain amount of the methane and water in the CHS in each hydrate formation experimental run. When the hydrate formation starts, the pressure inside the CHS decreases. The hydrate formation process lasts for 10-14 days, and then the pressure in the vessel is decreased to $13.5 \mathrm{MPa}$. Using the model of $\mathrm{Li}$ et al. [9], the hydrate saturation (the volume ratio of the hydrate and available pore space) is calculated as approximately $33.5 \%$ before the hydrate dissociation. By controlling the pressure decreases in the formation process, the different hydrate saturations could be obtained. In this work, all of the production experiments are carried out under a same saturation condition. The water in the preheater is heated up to the initial temperature of the hot water $\left(T_{i n j}\right)$, and then the bypass valve is opened to preheat the pipelines with hot water. After preheating, the bypass valve is closed. Subsequently, the inlet valve is opened for the heat injection. The gas production pressure controlled by the back-pressure regulator is set as 6.5 MPa. Before the heat injection starts, the system temperature is $8.0^{\circ} \mathrm{C}$. Using the fugacity model of Li et al. [22], the equilibrium hydrate dissociation pressure in the sediment at the working temperature of $8.0^{\circ} \mathrm{C}$ is calculated, and the calculated value is $5.7 \mathrm{MPa}$. Therefore, the set production pressure is higher than the equilibrium pressure, and the hydrate could not dissociate at this time. Then, the huff and puff cycles are carried out for hydrate dissociation.

The huff and puff method is a special method of the combination of depressurization and thermal stimulation for gas production from hydrate deposit $[23,24]$. Fig. 3 is a schematic of the huff and puff method for gas production from a hydrate reservoir, the typical huff and puff method consists of three stages: injection, soaking and production [25]. In the work, firstly, the heat injection starts by injecting hot water at $40 \mathrm{ml} / \mathrm{min}$ for some time. The inlet valve is closed after the heat injection, and the soaking starts, during which the system pressure rises slowly. When the pressure stops rising, the soaking stage comes to an end, and the gas production stage starts. The outlet valve of the well is opened, and when the system pressure drops to the set production pressure, the outlet valve is turned off. At this point, the current cycle of the gas production finishes, and the next cycle of thermal huff and puff experiment starts. When the pressure increase during soaking stage approaches 0 during the thermal huff and puff experiments, we believe that no more hydrate decomposition in the CHS. The system is closed for more than $2 \mathrm{~h}$ and then the system pressure is gradually released to atmospheric pressure. During the hydrate dissociation, the temperatures and pressure in the vessel, the gas production rate, the water injection and production rates are recorded at $10 \mathrm{~s}$ intervals.

In this work, a total of seven experimental runs were carried out to investigate the production behavior of methane hydrate in the

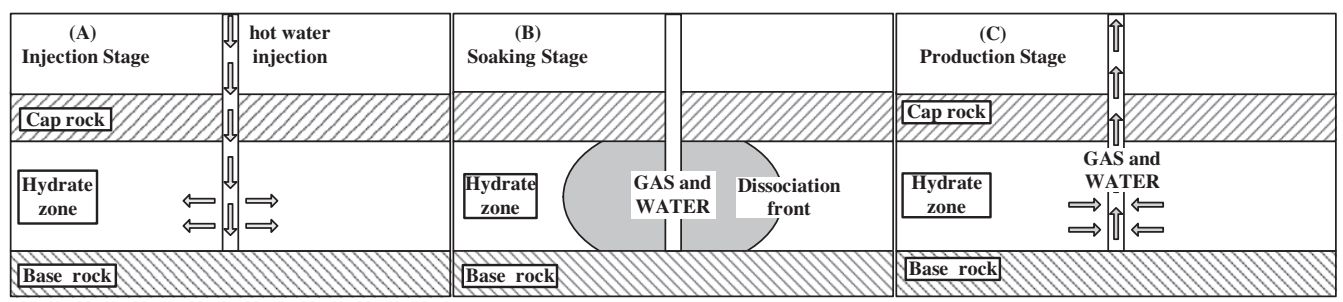

Fig. 3. Schematic of huff and puff method for gas production from a hydrate reservoir. 
Table 1

Experimental conditions of methane hydrate production by hot water huff and puff.

\begin{tabular}{|c|c|c|c|c|c|c|c|}
\hline Items & $\begin{array}{l}\text { Water bath } \\
\text { temperature } \\
\left({ }^{\circ} \mathrm{C}\right)\end{array}$ & $\begin{array}{l}\text { Production } \\
\text { pressure } \\
(\mathrm{MPa})\end{array}$ & $\begin{array}{l}\text { Temperature of } \\
\text { water injected }\left({ }^{\circ} \mathrm{C}\right)\end{array}$ & $\begin{array}{l}\text { Rate of water } \\
\text { injected }(\mathrm{ml} / \\
\text { min })\end{array}$ & $\begin{array}{l}\text { Time of water injected in each } \\
\text { huff and puff cycle (min) }\end{array}$ & $\begin{array}{l}\text { Saturation of } \\
\text { hydrate (\%) }\end{array}$ & $\begin{array}{l}\text { Number of huff } \\
\text { and puff cycles }\end{array}$ \\
\hline Run 1 & 8.0 & 6.5 & 8.0 & 40.0 & 5.0 & 0 & 1 \\
\hline Run 2 & 8.0 & 6.5 & 130.0 & 40.0 & 5.0 & 0 & 1 \\
\hline Run 3 & 8.0 & 6.5 & 130.0 & 40.0 & 5.0 & 33.5 & 15 \\
\hline Run 4 & 8.0 & 6.5 & 160.0 & 40.0 & 5.0 & 33.5 & 14 \\
\hline Run 5 & 8.0 & 6.5 & 190.0 & 40.0 & 5.0 & 33.5 & 10 \\
\hline Run 6 & 8.0 & 6.5 & 130.0 & 40.0 & 7.5 & 33.5 & 13 \\
\hline Run 7 & 8.0 & 6.5 & 130.0 & 40.0 & 10.0 & 33.5 & 11 \\
\hline
\end{tabular}

porous media by using the hot water huff and puff method with the central vertical wells. The experimental arrangement is shown in Table 1.

\section{Results and discussion}

\subsection{Production process}

\subsubsection{Pressure change}

Fig. 4 shows the changes of the system pressures for run 1, run 2 and the 3 rd cycle of run 3 with time. In runs 1 and 2, the methane is injected to pressurize the CHS to $6.5 \mathrm{MPa}$ at $8^{\circ} \mathrm{C}$. Because the time of methane injection is short, little hydrate forms in CHS in this case. Actually, the two experiments are the blank experiments without hydrate formation. The 3rd cycle of run 3 is a reference case. The other huff and puff cycles in each experiment show similar behaviors. The purpose of the blank experiments is to investigate the impact of the hot water injection in $\mathrm{CHS}$, and provide a judgment of the end of the hot water huff and puff experiment.

In the injection stage $(0-250 \mathrm{~s})$ for run 1 , the system pressure increases approximately from 6.50 MPa to 7.05 MPa with the injection of the cold water of $200 \mathrm{ml}$ with $8{ }^{\circ} \mathrm{C}$. It is due to the fact that the cold water injected takes gradually up the space in the CHS with a fixed volume, resulting in the methane gas compressed in the system. In the work, the biggest increasing degree of the system pressure during injection stage is called as PII. In the soaking stage $(250-850 \mathrm{~s})$ for run 1 , the pressure maintains at $7.05 \mathrm{MPa}$. This illustrates that the system has little mass transfer in the soaking process for run 1 . In the production stage (850-1250 s), the sys-

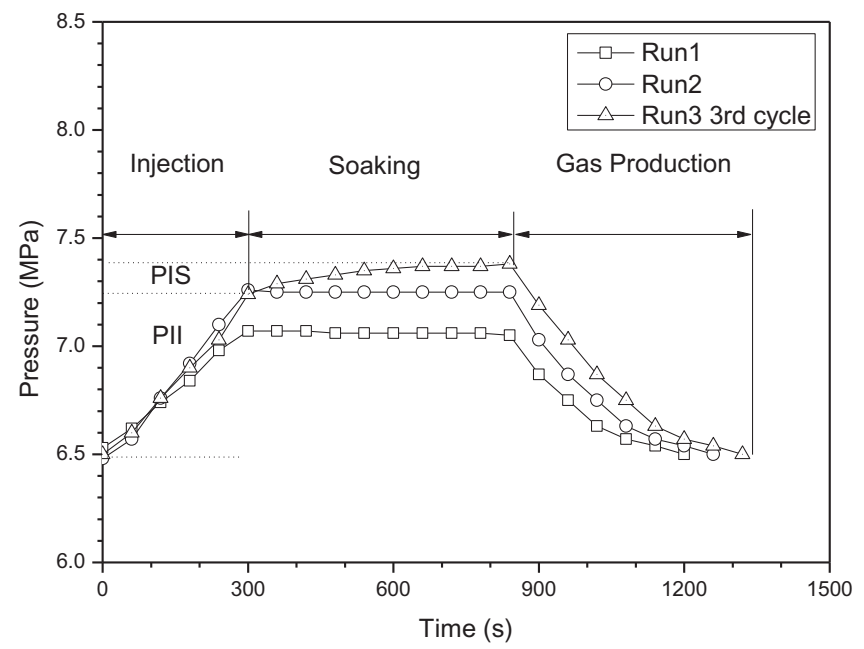

Fig. 4. Changes of system pressures for runs 1, 2, and the 3rd cycle of 3 . tem pressure decreases rapidly to the set production pressure (6.5 MPa).

In the injection stage (0-250 s) for run 2, with the injection of the hot water of $200 \mathrm{ml}$ with $130^{\circ} \mathrm{C}$, the system pressure increases from 6.50 MPa to 7.25 MPa. It is attributed to the fact that the gas in the CHS is compressed by the injected hot water, and the injected heat causes the raise of the free gas temperature in the CHS, resulting in the increase of the system pressure. In the soaking stage (250-850 s) for run 2 , the pressure maintains at $7.25 \mathrm{MPa}$. In the production stage (850-1250 s), the system pressure decreases rapidly to the set production pressure. The 3rd cycle huff and puff for the run 3 is carried out under the condition of the hydrate existing in the CHS. In the injection stage $(0-250 \mathrm{~s})$, the hot water of $200 \mathrm{ml}$ with $130{ }^{\circ} \mathrm{C}$ is injected into $\mathrm{CHS}$, and the system pressure increases from 6.50 MPa to $7.30 \mathrm{MPa}$. The reason for the increase of the system pressure is that the gas is compassed, the temperature is raised and the amount of gas increases on account of the hydrate dissociation in the CHS under the effect of the hot water injection. During the soaking stage $(250-850 \mathrm{~s})$, the pressure slowly increases from 7.30 MPa to 7.40 MPa. It is because the continuous decomposition of the hydrate as a result of continuous heat diffusion in the soaking process causes gas production and the increase in the system pressure. The system pressure stops increasing at $850 \mathrm{~s}$, which indicates that the hydrate stops decomposing. The soaking stage is ended at this time. The biggest increasing degree of the system pressure during soaking stage is called as PIS. In the production stage (850-1250 s), the system pressure decreases rapidly to the set production pressure (6.5 MPa).

The PII for runs 1 and 2 are $0.55 \mathrm{MPa}$ and $0.75 \mathrm{MPa}$, respectively. The PII for run 1 is caused by the water injection, while the PII for run 2 is as a result of water injection and heat injection. It can be found in Fig. 4 that the difference of the PII for runs 1 and 2 is only $0.2 \mathrm{MPa}$, which indicates that the pressure increase during injection stage is mainly attributed to the contribution of the water injection other than that of the heat injection. Compared with run 2, the PII of the 3rd cycle of the huff and puff process for run 3 are similar with that for run 2. It illustrates that little hydrate is decomposed in the injection stage of the 3rd cycle for run 3.

The PISs for runs 1 and 2 are 0 , because there are no hydrate for dissociation in the CHS, Thus, the system pressure has no change. However, the PIS of the 3rd cycle of the huff and puff for the run 3 is $0.1 \mathrm{MPa}$. This is because continuous decomposition of the hydrate and the gas production in the process result in the pressure increasing. As the number of cycles increases, the PIS approaches 0 at a certain cycle, which indicates that little hydrate decomposes during the soaking stage of this cycle. Therefore, it can be considered that the decomposition experiment with the huff and puff process has been completed when the PIS trends to zero at the certain cycle. This can be a criterion for determining the end of the decomposition experiment in the work.

As shown in Table 1, the injection temperature and the injection time (the duration of the hot water injection in each huff and puff) 
in run 3 are $T_{i n j}=130{ }^{\circ} \mathrm{C}$ and $t_{i n j}=5 \mathrm{~min}$, respectively. The run 3 includes 15 cycles of the huff and puff process under this condition. The injection time for runs 4 and 5 is the same with that for run 3 . However, the injection temperatures are $160^{\circ} \mathrm{C}$ and $190{ }^{\circ} \mathrm{C}$, respectively, and the runs 4 and 5 include 14 and 10 cycles of the huff and puff process, respectively. The injection temperature for runs 6 and 7 is the same with that for run 3 . However, the injection time is $7.5 \mathrm{~min}$ and $10 \mathrm{~min}$, respectively, and the runs 6 and 7 include 13 and 11 cycles, respectively. Thus, it can be found that the number of cycles of the huff and puff process decreases with the increase of the injection temperature. It is due to the fact that the higher injection temperature leads to the higher driving force for the hydrate dissociation, which enhances the hydrate dissociation rate. In addition, it can be also found that the higher injection time results in the smaller number of cycles of the huff and puff process, because the increase of the injection time means the increase of the amount of the heat injection, leading to the enlarging of the region impacted by the heat diffusion and the increase of the hydrate dissociation rate.

Fig. 5 shows the change of the PII and the PIS with the huff and puff cycles for runs 3-7. As seen in Fig. 5a, the values of the PII of the runs 3-5 are between $0.7 \mathrm{MPa}$ and $0.8 \mathrm{MPa}$, indicating that the injection temperature change has little effect on the PII. In addition, as the number of the cycles for each run increases, The PIS firstly increases, and then decreases. It may be because in the first few cycles of thermal huff and puff, the injected heat diffuses gradually from the production wellhead at the center to the surroundings, and the region in the CHS affected by the heat diffusion gradually increases and the spreading rate of the dissociation re-
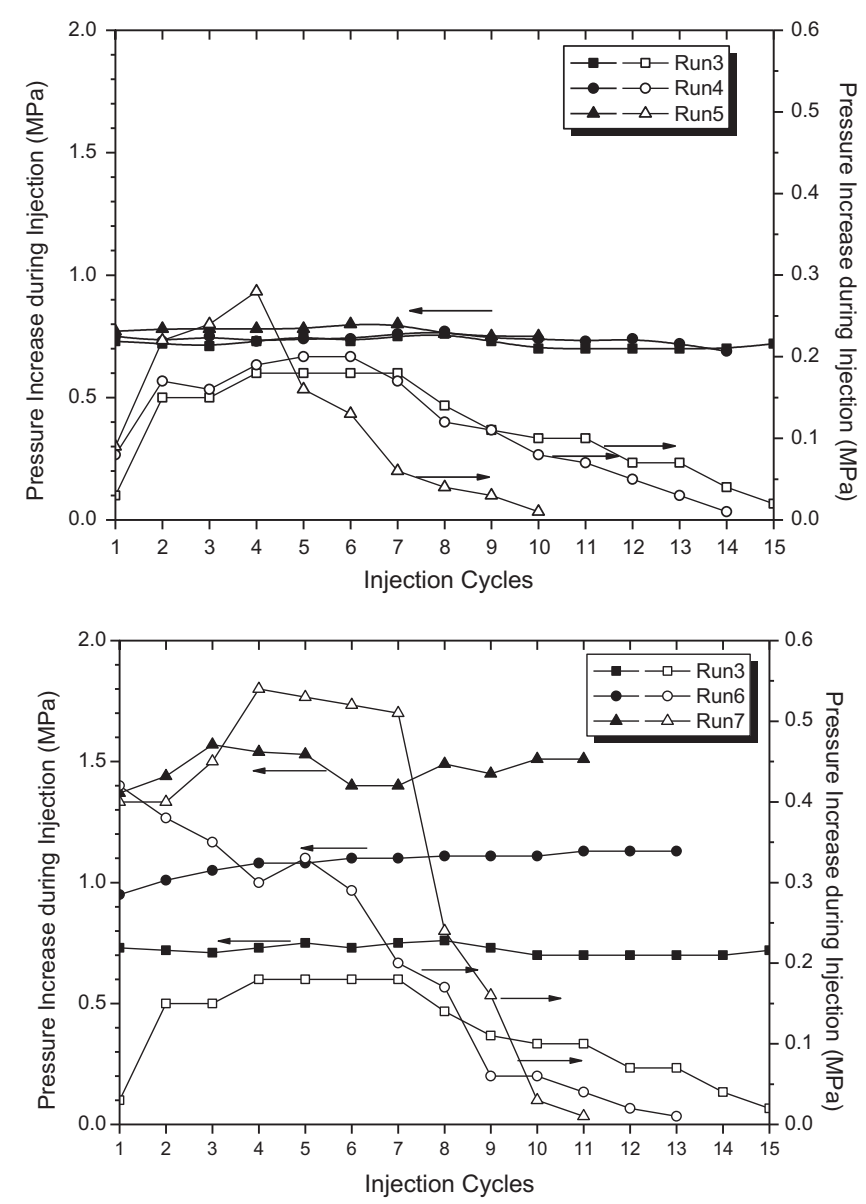

Fig. 5. Changes of PII and PIS with the huff and puff cycles for runs 3-7. gion also gradually increases with the heat injection, and thus, the amount of gas released from the hydrate dissociation and the gas production rate also gradually increases, resulting in the increase of the PIS. Afterwards, as the number of the cycles increases, the spreading rate of the dissociation region gradually decreases, resulting in the reductions of gas production rate and the amount of gas produced in the soaking stage, which leads to the decrease of the PIS. Eventually, the PIS approaches 0 , and the gas production is completed. It can be also seen from Fig. 5a that the higher injection temperature can cause the faster increase and decrease of the PIS. It is due to the higher injection temperature makes the bigger temperature driving force for the hydrate decomposition, resulting in the higher gas production rate and the amount of gas produced.

Fig. $5 \mathrm{~b}$ shows the change of the PII and PIS vs. the number of the huff and puff cycles for runs 3, 6, and 7 with the different injection time, which is $5 \mathrm{~min}, 7.5 \mathrm{~min}$, and $10 \mathrm{~min}$, respectively. As shown in Fig. 5b, the longer injection time leads to the higher PII at the fixed cycle. The longer injection time means the increase of the larger amount of the water injection. Thus, the injection of more fluid causes the gas in the CHS compressed more intensively, resulting in the system pressure increases. In addition, as seen in Fig. 5b, the change characteristics of the PISs for runs 3, 6 and 7 with the different injection time are similar those for runs 3-5 with the different injection temperatures. The higher injection time can lead to the faster increase and decrease of the PIS. Because the increase of the injection time means the increase of the amount of the heat injection, which makes the increase of the spreading region for dissociation impacted by the heat diffusion, and thus results in the increase of the amount of gas produced and the hydrate dissociation rate.

It is noted from Fig. 5a and b that the injection temperature has little effect on the PII while the injection time has an obvious effect on the PII, and the injection time has a bigger effect on the PIS than the injection temperature.

\subsubsection{Gas and water production}

The gas production from the hydrate reservoir has to accompany the water production. The water production requires to consume the energy under the field condition [26]. Thus, the volume of the produced gas as large as possible and the volume of the produced water as small as possible are expected to meet the requirement of the valuable commercial production.

Fig. 6a shows the changes of the cumulative volume of the produced gas and water with the huff and puff cycles for runs 3-5 with the different injection temperatures. As seen in Fig. 6a, there is the high gas production rate during the first 4-5 huff and puff cycles for each run. After that, the gas production rate gradually decreases as the number of cycle increasing. This is because that most of the injected heat quickly contacts with the hydrate reservoir in near-well region in the first few huff and puff cycles, mainly used for the hydrate decomposition in the near-well region. Thus the gas production rate is high. As the number of cycle increasing, the hydrate located around the central well completely decomposes. The hydrate in far-from-well region is also gradually decomposed because the heat continues to decompose the hydrate in the surroundings. However, the rate of hydrate decomposition also decreases, because of the heat loss through the boundary of the reactor, which leaves less capability to progress to the surroundings and to decompose hydrate, thus the rate of the gas production decreases. As the injection temperature increasing, the cumulative volume of the produced gas has increased accordingly. The reason is that the injection temperature increase leads to the enlarging of region impacted by heat diffusion, thus the region for gas hydrate decomposition enlarging results the cumulative volume of the produced gas increases. 

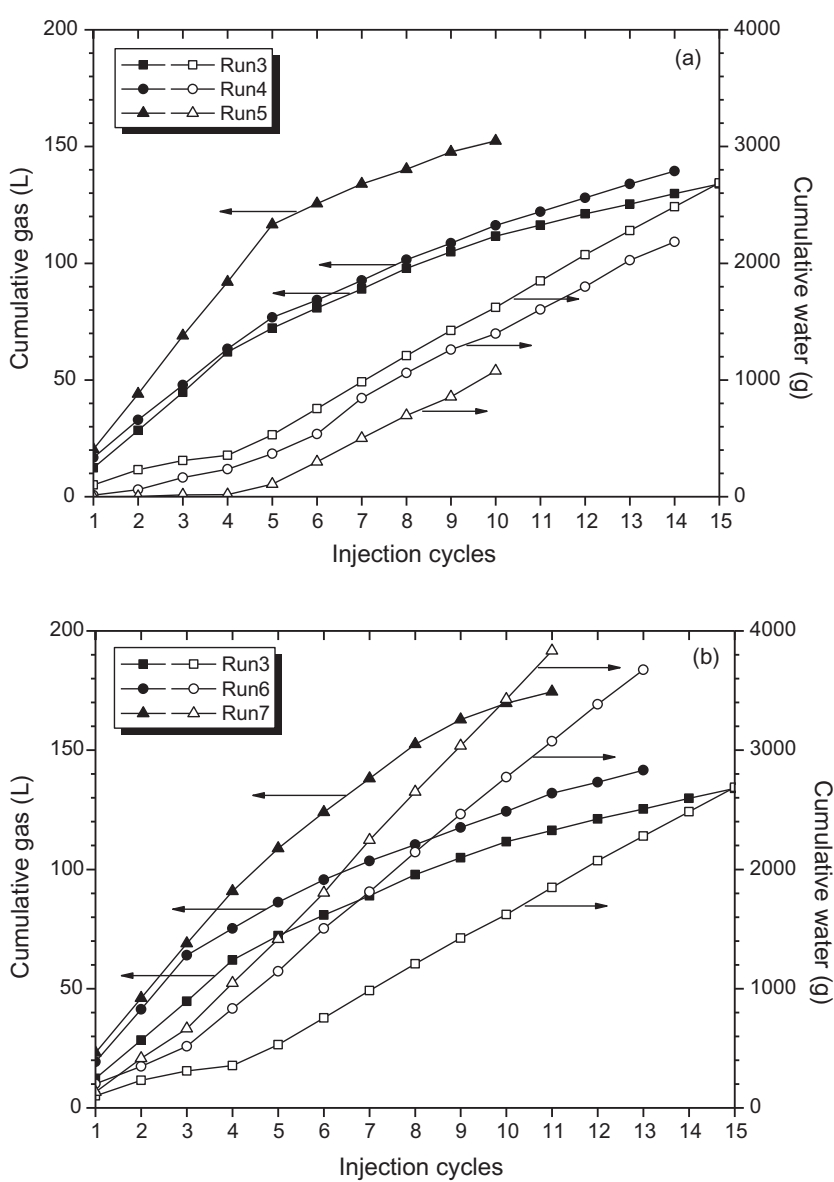

Fig. 6. Changes of cumulative volumes of produced gas and water with the cycles for runs 3-7.

There is the low water production rate during the first 4-5 huff and puff cycles for each run. However, after that, the water production rate gradually increases and tends towards stability. Finally, the volume of the produced water is similar with the volume of the injection water in each cycle. This is probably because that there are a lot of free pores in the CHS before the experiment begins, and the hydrate decomposed in the CHS during the first 4-5 huff and puff cycles led the free porosity increasing. Thus some of the injection water remains in the CHS. However, after this period, the free pores in the CHS are filled by injection water gradually and the amount of hydrate decomposition gradually decreases, and thus the injection water is equal to the production water during the remaining huff and puff cycles. Meanwhile, the higher injection temperature leads to the lower cumulative volume of the produced water, because the higher injection temperature causes the larger region for hydrate decomposition and higher rate of hydrate dissociation, which leads to the more free pores in the CHS. Therefore, the hot water remaining in the CHS increases.

Fig. $6 \mathrm{~b}$ shows the changes of the cumulative volume of the produced gas and water for runs 3,6, and 7 with the different injection time. The changes of the cumulative volume of the produced gas in these three experiments are similar with the changes in Fig. 6a: the cumulative volume of the produced gas increases rapidly in the first 4-5 huff and puff cycles, and then it gradually decreases. As the injection time increasing, the cumulative volume of the produced gas has increased accordingly, because the injection time increase causes the region impacted by heat diffusion enlarging, resulting in more hydrate decomposition.

Similar with Fig. 6a, in the first 4-5 huff and puff cycles for each run, the water production rate is low. After that, the water produc-

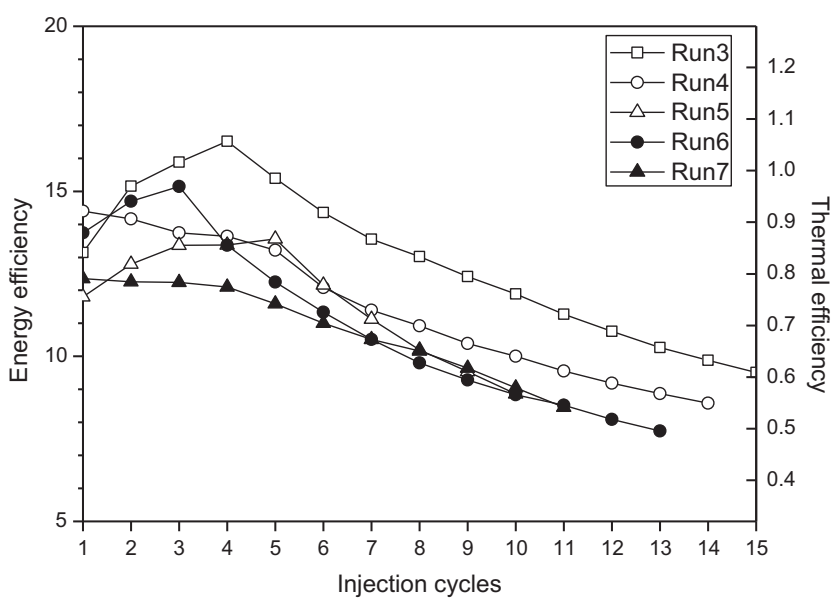

Fig. 7. Changes of thermal efficiency and energy efficiency with the cycles for runs $3-7$.

tion rate gradually increases and tends towards stability. Finally, the volume of the produced water is almost equal to the volume of the injection water in the remaining cycles. The reason is the same with that described as Fig. 6a. However, the higher injection time leads to the higher cumulative volume of the produced water, because the higher injection time means the more water injected into the CHS, causing more water removed out of the CHS.

\subsubsection{Thermal efficiency and energy efficiency}

In the work, the thermal efficiency and energy efficiency are employed to evaluate the efficiency of producing gas from the gas hydrate reservoir [27]. The thermal efficiency is defined as the ratio of the heat used for the hydrate dissociation to the total input heat. The energy efficiency is defined as the ratio of the combustion heat of the produced gas to the total input heat.

The energy efficiency can be calculated with the following equation:

$\xi=\frac{Q \cdot M_{\text {gas }}}{C_{w} \cdot M_{w} \cdot\left(T_{0}-t\right)}$

where $Q$ is the cumulative volume of the produced gas; $M_{w}$ is the mass of the injected hot water; $T_{0}$ is the temperature of the wellhead; $t$ is the ambient temperature $\left(8^{\circ} \mathrm{C}\right)$; the combustion heat of natural gas $\left(M_{\text {gas }}\right)$ is $37.6 \mathrm{MJ} / \mathrm{m}^{3}$; the specific heat of water $\left(C_{w}\right)$ is $4.2 \times 10^{3} \mathrm{~J} /(\mathrm{kg} \mathrm{K})$.

The thermal efficiency can be calculated with the following equation:

$\eta=\frac{m_{\text {diss }} \cdot M_{\text {hyd }}}{C_{w} \cdot M_{w} \cdot\left(T_{0}-t\right)}=\frac{\xi \cdot M_{\text {hyd }}}{22.4 \cdot M_{\text {gas }}}=0.064 \xi$

where $m_{\text {diss }}$ is the mole of the hydrate which has dissociated; the dissociation heat of the hydrate, $M_{h y d}$, is taken as $54.1 \mathrm{~kJ} / \mathrm{mol}$.

Fig. 7 shows the changes of the thermal efficiency and energy efficiency with the cycle number for runs 3-7. As seen in Fig. 7, there are the high thermal efficiencies and energy efficiencies for all runs in the first 4-5 cycles, and then they gradually decrease as the number of the remaining cycle increases. In other words, the optimum period for the gas production by using the thermal huff and puff method is during the first $4-5$ cycles. It can be suggested that other method for hydrate decomposition after the period should be employed to enhance the thermal efficiency and energy efficiency. In addition, it is noted from Fig. 7 that after the second cycle, both the thermal efficiency and the energy efficiency with each cycle for other runs, whether with the higher injection temperature (runs 4 and 5) or with the longer injection time (runs 6 and 7), are lower than those 


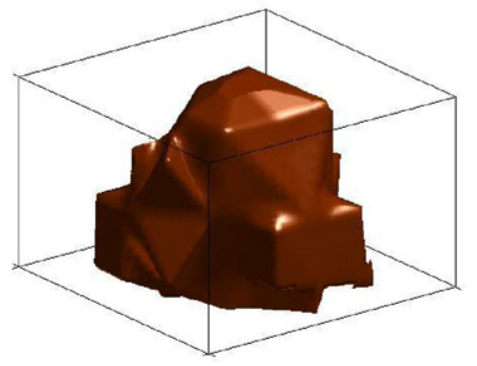

(a) 1 st cycle

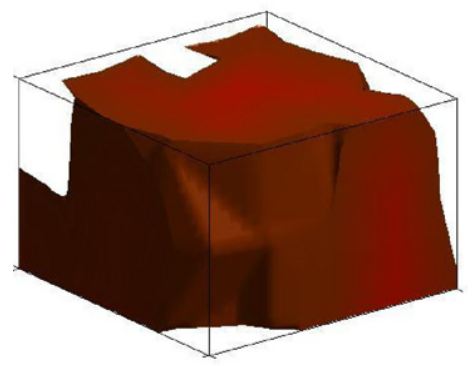

(c) 10th cycle

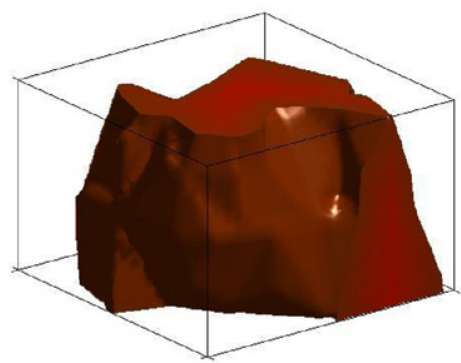

(b) 5th cycle

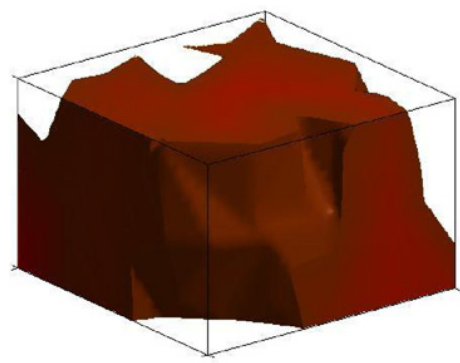

(d) 15 th cycle

Fig. 8. Decomposition boundaries at the ends of the $1 \mathrm{st}, 5$ th, 10 th, and 15 th soaking stages for run 3.

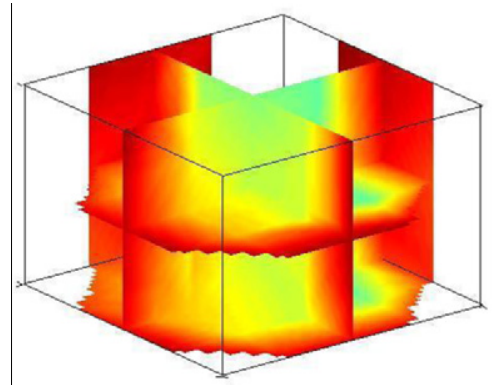

(a) 1 st cycle

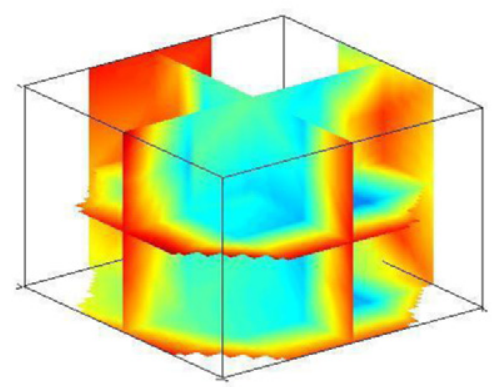

(c) 10th cycle

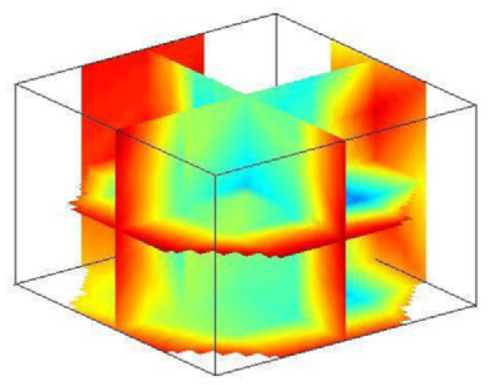

(b) 5th cycle

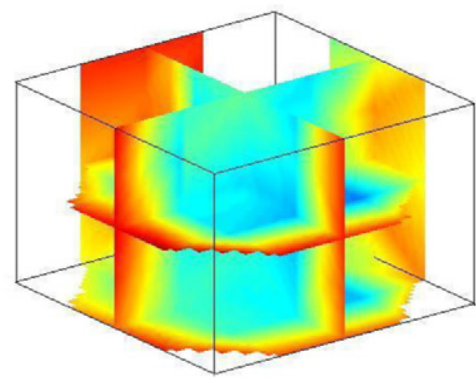

(d) 15 th cycle

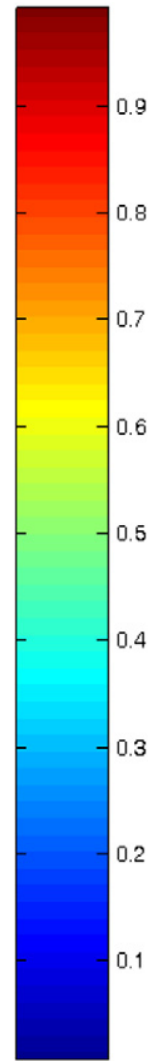

Fig. 9. Three-dimensional spatial resistance ratio distributions at the ends of the 1 st, 5 th, 10 th, and 15 th soaking stages for run 3.

for run 3. It is probably due to the fact that although the higher injection temperature and the longer injection time can trigger more amount of the produced gas and the shorter time for the gas produc- tion, the larger heat loss also occurs through the boundary of the $\mathrm{CHS}$, resulting in the reduction of the thermal efficiencies and the energy efficiencies. Thus, in the work, the highest thermal efficiency 
and energy efficiency can be obtained under the condition of the injection temperature of $130^{\circ} \mathrm{C}$ and injection time of $5 \mathrm{~min}$, based on the thermal huff and puff method.

\subsection{Moving boundary}

The hydrate decomposition is considered to exist a moving dissociation boundary [28]. The moving boundary separates the decomposed zone containing gas and water from the undecomposed zone containing the hydrate. During the huff and puff cycles, the moving boundary rapidly expands in the process of the heat injection, and is continuously expanding in the soaking stage [13].

The system pressure changes with time during the huff and puff process. The change of equilibrium hydrate decomposition temperature corresponding to the system pressure can be calculated with the fugacity model given by Li et al. [22]. Based on the equilibrium hydrate decomposition temperature at the certain time, a threedimensional isothermal surface can be given. Thus, we can approximately consider that the isothermal surface is a moving decomposition boundary. The temperatures of the region surrounded by the isothermal surface are higher than the equilibrium temperature,

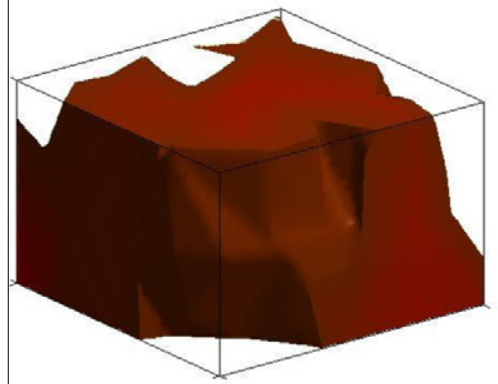

(a) Run3

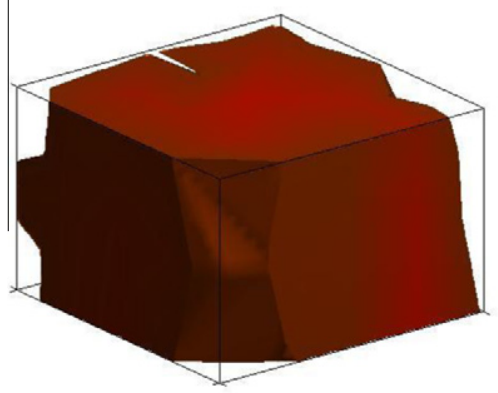

(c) Run 5 and this region is one for gas hydrate decomposition. The region outside the isothermal surface is not the hydrate decomposition region, in which the system temperature is lower than the equilibrium temperature.

Fig. 8 shows the decomposition boundaries at the ends of the soaking stages of the $1 \mathrm{st}, 5 \mathrm{th}, 10 \mathrm{th}$, and 15 th huff and puff cycles for run 3. It can be seen from Fig. 8 that the decomposition boundary rapidly expands from the 1 st to the 5th cycle, indicating that the heat flow is quickly spreading outward in the period, making the hydrate decomposition region expand rapidly. This is consistent with what discussed in Figs. 5 and 6. The expansion of the hydrate decomposition region progresses slowly from the 5th to the 10th cycle. Eventually, the hydrate decomposition region reaches its maximum influence in the 15th cycle. At this time, the hydrate surrounded by the decomposition boundary has been dissociated completely, the pressure stops increasing. Even if the heat huff and puff process continuously progresses, the hydrate decomposition region no longer further spreads out. Thus, the decomposition boundary at this time is "the maximum decomposition boundary". The region surrounded by the maximum decomposition boundary is the largest region for gas hydrate decomposition.

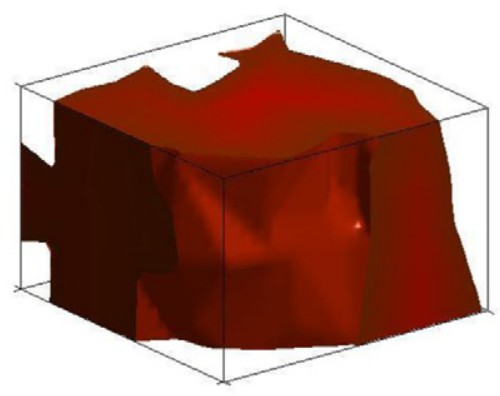

(b) Run 4

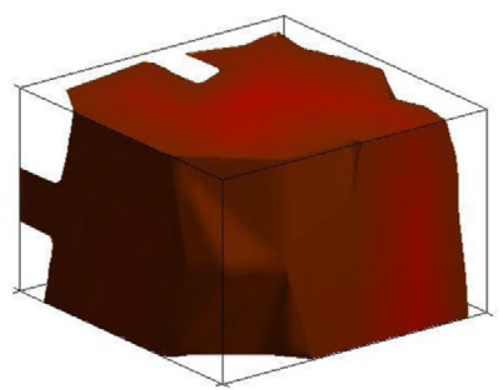

(d) Run 6

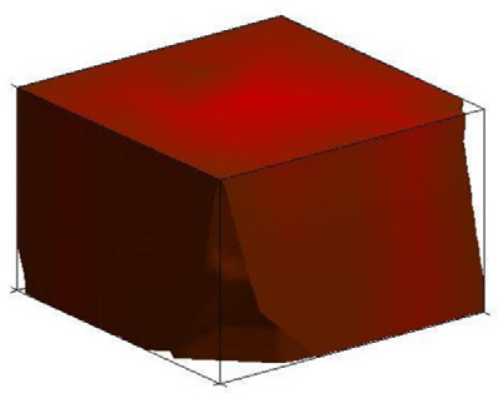

(e) Run 7

Fig. 10. Maximum decomposition boundaries for runs 3-7. 
The resistance can be used to characterize the change of the gas hydrate reservoir. Since the resistivity of gas hydrate is greater than water, generally the resistance decreases as the hydrate decomposes. In the work, we use the ratio between the real-time resistance during the experiment and the resistance before the experiment (referred to as the resistance ratio) as a characterization parameter. Fig. 9 shows the three-dimensional spatial resistance ratio distributions at the ends of the $1 \mathrm{st}, 5$ th, 10 th, and 15th soaking stages for run 3. As seen in Fig. 9, the resistance ratios decrease dramatically in most regions in the hydrate reservoir from the 1 st to the 5 th cycle, indicating that the hydrate decomposing regions rapidly expands from the 1 st to the 5 th cycle. The resistance ratios decrease slowly in some region from the 5th to 10th cycle. That is to say, the hydrate decomposition region progress slowly in the process. The resistance ratio distribution in the reservoir has little change from the 10th to 15th cycle, indicating the hydrate decomposition region in the process make little progress. This also means that the hydrate decomposition region has reached its maximum range at the 10 th and 15 th cycles, and the hydrate outside the region no longer decomposes. Compare with Fig. 8, the change characteristics of resistance ratio distributions is similar with that of the decomposition boundary, verifying the existence of the decomposition boundary in thermal huff and puff process. In addition, the decomposition boundaries and the resistance ratio distributions in other experiments are similar with run 3.

Fig. 10 shows the maximum decomposition boundary for runs 3-7. As shown in Fig. 10a-c, the maximum decomposition boundary increases with the increase of the injection temperature at the fixed injection time for runs 3-5. In addition, it can be seen from Fig. 10a, d, and e that the maximum decomposition boundary increases with the increase of injection time at the fixed injection temperature for runs 3, 6 and7. Thus, it is concluded that the hydrate decomposition region spreads out with the increase of the injection temperature and the injection time. It is well agreement with the result achieved in Fig. 6. Meanwhile, Fig. 10 also shows that the decomposition boundary is not completely symmetrical, indicating that the diffusion of the injected heat is not completely isotropic when the heat flux is transferred from the center well to the surroundings via the flow and conduction through the porous media, which may be as a result of the differences in the hydrate saturation, the porosity of the sediment or the permeability of the sediment in the local region.

\section{Conclusions}

In this work, the novel developed three-dimensional cubic hydrate simulator (CHS) for the production of gas hydrate is used to investigate into the decomposition behaviors of methane hydrate during the thermal huff and puff experiments through a single vertical well. The following conclusions are obtained:

(1) The system pressures are analyzed by using the PII and PIS, indicating that the injection time have more remarkable effect on the system pressure than the injection temperature.

(2) As the number of cycle increasing, the rate of gas production decreases, whereas the rate of water production increases at the initial stage, and then tends to be constant. The increases of injection temperature and injection time both can enhance the cumulative volume of the produced gas. Meanwhile, the higher injection temperature leads to the smaller volume of the produced water, whereas the higher injection time leads to the bigger volume of the produced water.
(3) The injection temperature and injection time increasing may not obtain a better economic effectiveness during hydrate dissociation by using the thermal huff and puff method. The optimum period for gas production in each experimental run is the first 4-5 huff and puff cycles. The highest thermal efficiency and energy efficiency can be obtained with the injection temperature of $130{ }^{\circ} \mathrm{C}$ and injection time of 5 min.

(4) The hydrate decomposition is an expanding process of the moving decomposition boundary, and there is a maximum decomposition boundary in the process. Meanwhile, the injected heat does not diffuse isotropically in the hydrate reservoir.

\section{Acknowledgments}

This work was supported by National Natural Science Foundation of China (Grants 51076155 and 51004089) and Science \& Technology Program of Guangdong Province (Grant 2009B050600006), which are gratefully acknowledged.

\section{References}

[1] Sloan ED. Fundamental principles and applications of natural gas hydrates. Nature 2003;426:353-9.

[2] Klauda JB, Sandler SI. Global distribution of methane hydrate in ocean sediment. Energy Fuel 2005;19:459-70.

[3] Lee SY, Holder GD. Methane hydrates potential as a future energy source. Fuel Process Technol 2001;71:181-6.

[4] Collett TS. Gas hydrates as a future energy resource. Geotimes 2004;49:24-7.

[5] Castaldi MJ, Zhou Y, Yegulalp TM. Down-hole combustion method for gas production from methane hydrates. J Petrol Sci Eng 2007;56:176-85.

[6] Li XS, Wan LH, Li G, Li QP, Chen ZY, Yan KF. Experimental investigation into the production behavior of methane hydrate in porous sediment with hot brine stimulation. Indust Eng Chem Res 2008;47:9696-702.

[7] Makogon TY, Larsen R, Knight CA, Sloan ED. Melt growth of tetrahydrofuran clathrate hydrate and its inhibition: method and first results. J Cryst Growth 1997; 179:258-62.

[8] Ahmadi G, Ji CA, Smith DH. Production of natural gas from methane hydrate by a constant downhole pressure well. Energy Convers Manage 2007;48:2053-68.

[9] Li G, Li XS, Tang LG, Zhang Y. Experimental investigation of production behavior of methane hydrate under ethylene glycol injection in unconsolidated sediment. Energy Fuel 2007;21:3388-93.

[10] Hirohama S, Shimoyama Y, Wakabayashi A, Tatsuta S, Nishida N. Conversion of CH4-hydrate to CO2-hydrate in liquid CO2. J Chem Eng Jpn 1996;29:1014-20.

[11] Hamaguchi R, Nishimura Y, Matsukuma Y, Minemoto M, Watabe M, Arikawa K. Gas-liquid two-phase pipe flow analysis of methane hydrate recovery system using gas-lift system. Kagaku Kogaku Ronbun 2005;31:68-73.

[12] Moridis GJ, Collett TS, Boswell R, Kurihara M, Reagan MT, Koh C, et al. Toward production from gas hydrates: current status, assessment of resources, and simulation-based evaluation of technology and potential. SPE Reservoir Eval Eng 2009;12:745-71.

[13] Li XS, Wang Y, Li G, Zhang Y, Chen ZY. Experimental investigation into methane hydrate decomposition during three-dimensional thermal huff and puff. Energy Fuel 2011;25:1650-8.

[14] Acharyya SK. Comment on: "Mobility of arsenic in West Bengal aquifers conducting low and high groundwater arsenic. Part I: comparative hydrochemical and hydrogeological characteristics" by Bibhash Nath, Doris Stuben, Sukumar Basu Mallik, Debashis Chatterjee, Laurent Charlet. Appl Geochem 2009;24:184-5.

[15] Chand S, Minshull TA. The effect of hydrate content on seismic attenuation: a case study for Mallik 2L-38 well data, Mackenzie delta, Canada. Geophys Res Lett 2004;31.

[16] Riedel M, Bellefleur G, Dallimore SR, Taylor A, Wright JF. Amplitude and frequency anomalies in regional 3D seismic data surrounding the Mallik 5L-38 research site, Mackenzie Delta, Northwest Territories. Canada Geophys 2006;71:B183-91.

[17] Sasaki K, Ono S, Sugai Y, Ebinuma T, Narita H, Yamaguchi T. Gas production system from methane hydrate layers by hot water injection using dual horizontal wells. J Can Petrol Technol 2009;48:21-6.

[18] Leaute RP, Carey BS. Liquid addition to steam for enhancing recovery (LASER) of bitumen with CSS: results from the first pilot cycle. J Can Petrol Technol 2007;46:22-30.

[19] Sayegh SG, Maini BB. Laboratory evaluation of the Co2 Huff-N-puff process for heavy oil-reservoirs. J Can Petrol Technol 1983;22:32. 
[20] Vittoratos E. Flow regimes during cyclic steam stimulation at cold lake. J Can Petrol Technol 1991;30:82-6.

[21] Guan JN, Liang DQ Wu NY, Fan SS. The methane hydrate formation and the resource estimate resulting from free gas migration in seeping seafloor hydrate stability zone. J Asian Earth Sci 2009;36:277-88.

[22] Li XS, Zhang Y, Li G, Chen ZY, Yan KF, Li QP. Gas hydrate equilibrium dissociation conditions in porous media using two thermodynamic approaches. J Chem Thermodyn 2008;40:1464-74.

[23] Bayles GA, Sawyer WK, Anada HR, Reddy S, Malone RD. A steam cycling mode for gas-production from a hydrate reservoir. Chem Eng Commun 1986;47:225-45.

[24] Li GMGJ, Zhang K. The Use of huff and puff method in a single horizontal well in gas production from marine gas hydrate deposits in the Shenhu area of the
South China Sea 2010 international oil and gas conference and exhibition. Beijing, China; 2010.

[25] Ceyhan N, Parlaktuna M. A cyclic steam injection model for gas production from a hydrate reservoir. Energy Source 2001;23:437-47.

[26] Marcano L, Gasbarri S, Gonzalez E. ISIS-INT (R): mechanistic system to predict well performance in intermittent artificial gas lift. Vis Technol 2000;7:83-6.

[27] Li G, Tang L, Huang C, Feng Z, Fan S. Thermodynamic evaluation of hot brine stimulation for natural gas hydrate dissociation. Huagong Xuebao/J Chem Indust Eng (China) 2006;57:2033-8.

[28] Selim MS, Sloan ED. Hydrate dissociation in sediment. SPE Reservoir Engineering (Society of Petroleum Engineers); 1990;5:7p 16859-7p. 